\section{Children's Active and Passive Interactions with Plants Influence Their Attitudes and Actions toward Trees and Gardening as Adults}

\author{
Virginia I. Lohr ${ }^{1}$ and Caroline H. Pearson-Mims²
}

\begin{abstract}
ADDITIONAL INDEX WORDs. benefits of trees, community forestry, environment, human issues in horticulture, human well-being, people-plant interactions, response to nature, survey, urban forestry, youth

Summary. A nationwide phone survey of attitudes toward urban trees, participation in civic or educational activities, and memories of childhood experiences with gardening and nature was conducted with 2004 adults in large urban areas. We analyzed the influence of 11 childhood experiences and five adult demographic characteristics on three items: "Trees in cities help people feel calmer," "Do trees have a particular personal, symbolic, or spiritual meaning to you?" and "During the past year, have you participated in a class or program about gardening?" Growing up next to natural elements such as flower beds, visiting parks, taking environmental classes, and gardening during childhood were associated with stronger adult attitudes and more actions. Growing up next to urban elements, such as large buildings, had a small, but opposite, influence. Demographics played a role in adult attitudes and actions. While both passive and active interactions with plants during childhood were associated with positive adult values about trees, the strongest influence came from active gardening, such as picking flowers or planting trees. These results indicate that horticultural programs for children raised in urban surroundings with few or no plants can be effective in fostering an appreciation for gardening in adults.
\end{abstract}

$\mathrm{H}$ istorically, gardening has been an important part of family life; children have helped plant, weed, and harvest. Today, formal children's gardens are very popular in the United States, being found in elementary schools, arboretums, and community gardens (DeMarco et al., 1999; Eberbach, 1990). Programs to promote interaction between children and nature are also popular, with nature camps, tree planting programs, and environmental projects being plentiful (Waliczek et al., 2003). Sponsors of such programs hope that these children will develop a "sense of kinship and respect for the natural world" that they will still have when they are adults (Lewis, 1996).

Department of Horticulture and Landscape Archi tecture, Washington State University, Pullman, WA 99164-6414

This research protocol was approved by the WSU Human Subjects Institutional Review Board. Financial support was provided in part by the U.S. Department of Agriculture Forest Service Urban and Community Forestry Program on the recommendation of the National Urban and Community Forestry Advisory Council.

${ }^{1}$ Professor.

${ }^{2}$ Research Technologist.
More than $80 \%$ of the U.S. population now lives in urban areas (U.S. Census Bureau, 2000). Europe and Latin America are also highly urbanized, at $75 \%$, and worldwide almost $50 \%$ of the population lives in urban areas (United Nations, 2001). More and more children today are being raised in these areas, which offer few easy opportunities for interactions with nature or gardening. This has increased the call for formal gardening programs with inner-city children (Relf

Nature education and outdoor experiences help children gain a respect for living things, stimulate their curiosity, and provide them with meaningful life experiences (Cooper Marcus, 1992; Bullock, 1994). Gardening and environmental education programs promote positive attitudes toward the environment in elementary school children (Jaus, 1984; Skelly and Zajicek, 1998; Waliczek and Zajicek, 1999). These programs also offer opportunities for hands-on, or active, learning experiences that encourage higher-order thinking and problem solving (Athman and Monroe, 2001; Waliczek et al., 2003). Little is known and Lohr, 2003). about the long-term effects of such programs, because longitudinal studies are costly and time consuming.

The goal of this project was to examine the relationship between childhood contact with nature and adult attitudes toward plants. Are children that have extensive experiences with nature more likely to understand and appreciate the values of gardening when they are adults? Will early interventions with plants translate into positive adult responses to nature? The objective of this project was to determine the relationship between adult memories of childhood contact with plants and adult attitudes toward trees and gardening among residents of large metropolitan areas in the U.S.

\section{Methods}

A nationwide telephone survey was prepared by the authors with assistance from John Tarnai and Don Dillman of the Washington State University Social and Economic Sciences Research Center (SESRC). Participants were surveyed about their attitudes toward urban trees, participation in activities such as community service, and childhood experiences with gardening and nature. Demographic information was also gathered.

The population was respondents 18 years old and older in households with telephones in the 112 most-populated metropolitan areas in the continental U.S., including Los Angeles, Calif.; Chicago, Ill.; and Atlanta, Ga. A sample combining randomly generated and directory listed telephone numbers was purchased from Genesys Sampling Systems of Fort Washington, Pa. The survey was administered by the SESRC using a computer-assisted telephone interviewing system. A pretest of the survey was administered to respondents to assess reactions to the questions, estimate the length of the interview, and determine how difficult it would be to reach respondents. Following the pretest, the number of questions was reduced to shorten the time for the interview and to remove confusing items. For the full survey, call attempts alternated day of the week and time of the day. The survey was completed in 13 weeks, and the response rate was $51.8 \%$. The final sample consisted of 2004 completed interviews, averaging 23 min long. The sampling error was $\pm 2.2 \%$ for binomial variable questions. Bias in the sampling was examined by 
comparing demographics of the sample to known characteristics of residents of metropolitan areas; they were similar, indicating that the sample was a good representation of the population.

We analyzed the influence of 11 childhood experiences on adult responses to three survey items: "Trees in cities help people feel calmer" (a social value), "Do trees have a particular personal, symbolic, or spiritual meaning to you?" (an intrinsic value), and "During the past year, have you participated in a class or program about gardening?" (an action). The 11 childhood experiences included being raised next to natural or urban elements, participating in environmental action or education, interacting passively with plants, such as visiting parks, and interacting actively with plants, such as picking flowers. Comparisons of adult responses with five demographic variables were also examined. A childhood experience or adult demographic was compared with an adult survey item using a chi-square statistic from a two-way frequency table. The relative strength of childhood experiences and adult demographics in predicting adult responses was examined using a logistic regression analysis, a form of multivariate analysis (SAS Institute, 1999). For the logistic regression, the 11 childhood variables were combined into five composite variables.

\section{Results and discussion}

Respondents ranged from 18 to 90 years old with a mean age of 42 years, and $56 \%$ were female. Less than half had completed a 4 -year college degree, $60 \%$ had an annual income of $\$ 50,000$ or less, and a majority identified themselves as White/European. Most respondents had lived next to trees or gardens as children, while onethird grew up next to urban elements, such as large buildings. As adults, most respondents continued to live near plants, but more than half now lived next to urban elements.

CHILDHOOD EXPERIENCES: HOME SURROUNDINGs. Respondents were asked about natural elements that surrounded their childhood homes. Of those from a childhood home "next to a garden or flower beds," $65 \%$ strongly agreed that trees are calming, while only $56 \%$ of those from a home not "next to a garden or flower beds" strongly agreed (Table 1 ). This showed that childhood surroundings could influence adult attitudes on the social benefits of trees. Respondents with a childhood home next to a garden were more likely than those not next to them to say that trees had "a particular personal, symbolic, or spiritual meaning," thus showing that adult attitudes toward the intrinsic value of trees could also be influenced by raising children next to gardens. This finding provides support for the value of inner city planting projects such as Philadelphia Green (Lewis, 1996).

Attitudes may be strongly held and resistant to change, or they may be weakly felt and subject to fluctuation. Strongly held attitudes are more likely to be expressed in actions or behavior than weak ones (Schwarz and Tesser, 2001). Being raised next to a garden affected adult actionsas well as attitudes (Table 1). Of the respondents wholived in homes by gardens during childhood, $11 \%$ reported taking a gardening class in the last year, while only $6 \%$ of those whose childhood home was not by a garden reported doing so. This clearly showed that living near a garden during childhood was a significant predictor of interest in gardening in adulthood.

Being raised "next to woods or forest" did not influence adult attitudes on the calming value of trees, which was a social benefit, or the likelihood of taking a gardening class (Table 1 ). It did influence adult attitudes on the personal meaning of trees, which was an intrinsic value. Perhaps being around woods or forests is a more solitary way of interacting with nature while gardening is more social, and this may have been reflected in these results.

We next examined the influence of being raised near urban elements. Living "next to large buildings" or "busy streets" as a child did not affect adult attitudes toward the calming nature of trees, but did affect feelings about their intrinsic value, with fewer of these respondents saying that trees had personal meaning than those whose homes were not next to large buildings or busy streets (Table 1). Being raised "next to large buildings" did not affect adult participation in gardening programs, but being raised "next to busy streets" reduced the likelihood of taking a gardening class. These results indicated that being raised near urban elements could affect adult attitudes and actions.

CHILDHOOD EXPERIENCES: ENVIRONMENTAL EDUCATION AND ACTION.
Most of us assume that childhood education about gardening or nature favorably affects adults' attitudes toward plants. We looked at this relationship by asking people if they had participated in such programs. For adults who had participated in "nature or environmental education in elementary school," the effects on attitudes toward the social and intrinsic values of trees and on taking a gardening class were strong (Table 1). Participating in "organized activities to improve the local environment" as a child also influenced attitudes toward the social and intrinsic values of trees, but not the likelihood of taking a gardening class.

Childhood experiences: PasSIVE INTERACTION WITH PLANTS. We looked at relationships between passive childhood exposure to trees and adult attitudes by asking people how often they spent time in outdoor places with trees or visited parks as children. Adults who very often were outdoors with trees appreciated the calming value of trees more than those who did so less often, but visiting parks had no effect on this (Table 1 ). Both spending time around trees and playing in parks were significant influences on people's perceptions of the personal meaning of trees. These results are consistent with previous studies of adult environmentalists, who overwhelmingly reported that childhood experiences contributed to their concerns for the environment (Palmer, 1993; Tanner, 1980). The results of this study, which was not restricted to environmentalists, confirmed that formative experiences with nature also influence values among the general public. Spending time around trees and playing in parks often were associated with an increased likelihood of taking gardening classes as an adult as well. These results demonstrated that passive childhood nature interactions could have a strong impact on adult attitudes and actions.

CHILdHOOd EXPERIENCES: Active GARDENING. To examine whether adult attitudes or actions might be affected by gardening during childhood, we asked adults how often they had spent time "picking flowers, fruits, or vegetables from a garden"; "planting trees, seeds, or plants"; or "taking care of indoor or outdoor plants" as children. Increased frequency of each of these activities had a strong influence on the three adult attitudes and actions (Table 1). 
Table 1. Proportion of respondents agreeing that trees in cities are calming, that trees have personal value, or that they had taken a gardening class or program during the past year, based on childhood experiences with plants.

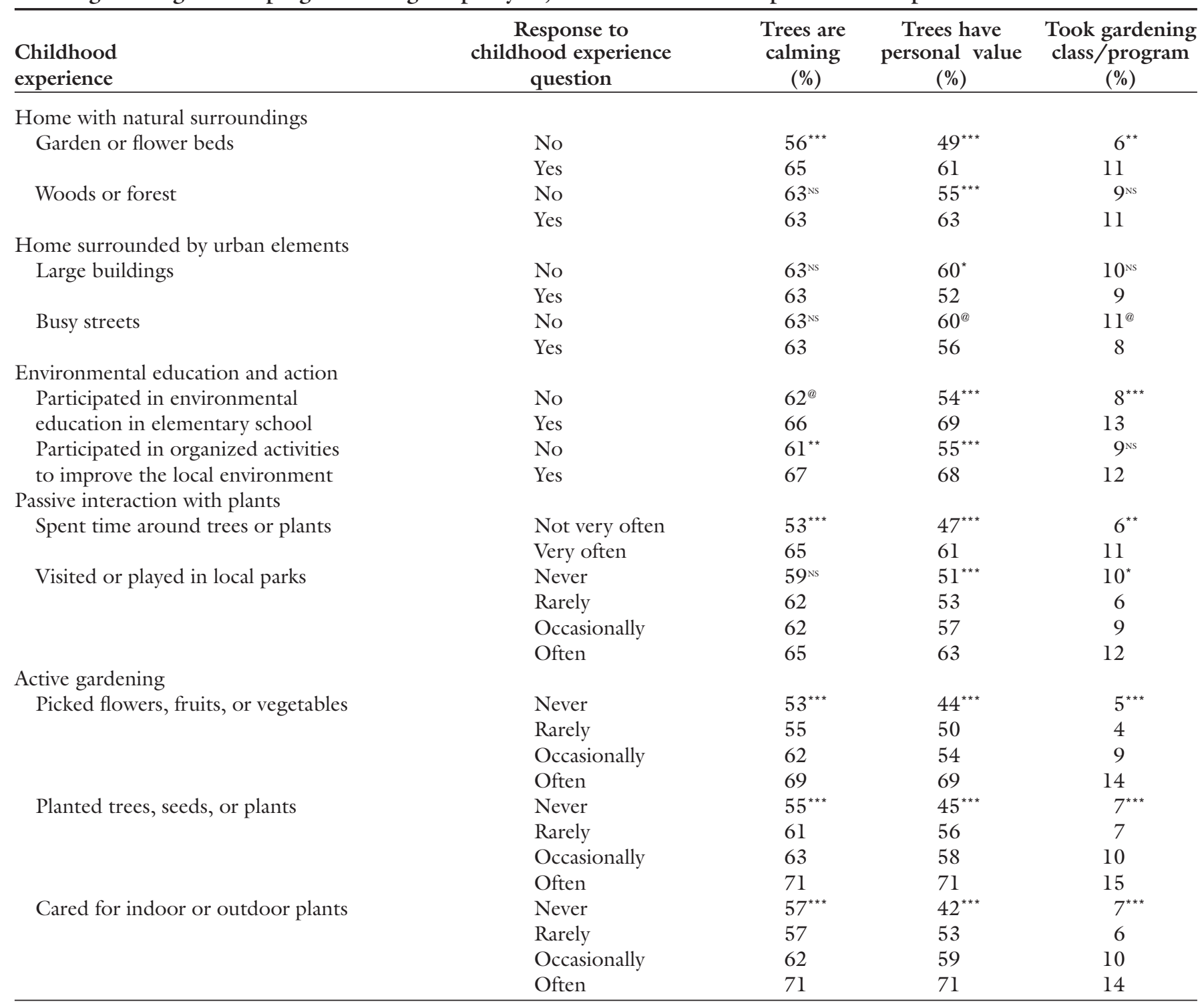

Ns, @, ${ }^{*},{ }^{* *},{ }^{* *}$ For each childhood experience, numbers within the column are not significantly different or are significantly different based on a chi-square statistic at $P \leq 0.10$, $0.05,0.01$, or 0.001 , respectively.

For example, $71 \%$ of adults who often planted trees, seeds, or plants as a child felt that trees had personal meaning, while only $45 \%$ of those who never did so felt this way about trees. Adults who had often cared for plants when they were children were twice as likely to have participated in a gardening class or program during the past year than those who had never done so. These results show the important influence of active childhood involvement with plants on adults.

Adult Demographics. Demographics influenced the responses to some of the survey items (Table 2). Age was a factor in all three items, with older people usually having stronger attitudes than younger people. The more education a person had, the more likely they were to have taken a gardening class during the past year. Ethnicity was a factor in appreciating the calming value of trees. While respondents of all ethnicities held positive attitudes toward trees, with nearly $50 \%$ in each ethnic group strongly agreeing that trees helped people feel calmer, Asian and African Americans generally felt this less strongly than Whites or Native Americans. Earlier studies have also documented differences among ethnic groups regarding the value of nature (Kellert, 1996). Ethnicity was not a factor in attitudes toward the personal meaning of trees, but was a factor in participation in gardening classes or programs, with Native Americans being the most likely to have participated. Gender and income were factors in attitudes, but not actions. Women were more likely than men to express appreciation for the social and intrinsic values of trees, as were respondents with annual incomes between $\$ 30,000$ and $\$ 50,000$ compared to respondents in other income categories.

RELATIVE IMPORTANCE OF DIFFERENT VARIABLES. Among the 10 variables selected to compare the relative importance of childhood experiences and adult demographics on adult attitudes and actions, both childhood experiences and adult demographics were shown to be important in explaining people's responses about the calming nature of trees (Table 3). In this analy- 
Table 2. Proportion of respondents agreeing that trees in cities are calming, that trees have personal value, or that they had taken a gardening class or program during the past year, based on adult demographics.

\begin{tabular}{|c|c|c|c|c|}
\hline $\begin{array}{l}\text { Adult } \\
\text { demographic }\end{array}$ & Response & $\begin{array}{l}\text { Trees } \\
\text { are } \\
\text { calming } \\
(\%)\end{array}$ & $\begin{array}{c}\text { Trees have } \\
\text { personal } \\
\text { value } \\
(\%)\end{array}$ & $\begin{array}{c}\text { Took } \\
\text { gardening } \\
\text { class } / \text { program } \\
(\%)\end{array}$ \\
\hline \multirow[t]{5}{*}{ Age } & $18-21$ years & $53^{* * *}$ & $49^{* * *}$ & $8^{* * *}$ \\
\hline & $22-30$ years & 55 & 51 & 4 \\
\hline & $31-40$ years & 63 & 57 & 9 \\
\hline & $41-55$ years & 68 & 62 & 14 \\
\hline & Over 55 years & 66 & 62 & 9 \\
\hline \multirow[t]{4}{*}{ Education } & High school or less & $61^{\mathrm{Ns}}$ & $57^{\mathrm{Ns}}$ & $6^{*}$ \\
\hline & 2 -year degree or less & 63 & 58 & 10 \\
\hline & 4-year degree or less & 65 & 59 & 12 \\
\hline & Some graduate school or more & 64 & 62 & 13 \\
\hline \multirow[t]{6}{*}{ Ethnicity } & Asian American/Pacific Islander & $54^{* * *}$ & $56^{\mathrm{NS}}$ & $12^{\circledR}$ \\
\hline & Black/African American & 48 & 55 & 10 \\
\hline & Hispanic/Latino & 60 & 57 & 9 \\
\hline & Multi-ethnic/Other & 60 & 60 & 7 \\
\hline & Native American & 68 & 60 & 22 \\
\hline & White/European American & 65 & 59 & 10 \\
\hline \multirow[t]{2}{*}{ Gender } & Female & $67^{* \star *}$ & $65^{* * *}$ & $11^{\mathrm{NS}}$ \\
\hline & Male & 58 & 50 & 9 \\
\hline \multirow{5}{*}{$\begin{array}{l}\text { Annual } \\
\text { income }\end{array}$} & Under $\$ 20,000$ & $60^{*}$ & $57^{*}$ & $8^{\mathrm{Ns}}$ \\
\hline & Over $\$ 20,000$ up to $\$ 30,000$ & 63 & 57 & 9 \\
\hline & Over $\$ 30,000$ up to $\$ 50,000$ & 69 & 65 & 11 \\
\hline & Over $\$ 50,000$ up to $\$ 75,000$ & 62 & 57 & 11 \\
\hline & Over $\$ 75,000$ & 62 & 54 & 11 \\
\hline
\end{tabular}

$\widehat{N s, @, *, \star \star, \star \star *}$ For each adult demographic, numbers within the column are not significantly different or are significantly different based on a chi-square statistic at $P \leq 0.10,0.05,0.01$, or 0.001 , respectively.

Table 3. The relative influence of selected childhood experience and demographic variables in explaining responses to items that trees in cities are calming, that trees have personal value, or that respondents had taken a gardening class or program during the past year.

\begin{tabular}{lcc}
\hline & $\begin{array}{c}\text { Trees are } \\
\text { calming }\end{array}$ & $\begin{array}{c}\text { Trees have } \\
\text { personal value }\end{array}$ \\
\cline { 2 - 3 } Variable & Order in the model $^{\mathrm{z}} /$ program \\
\hline
\end{tabular}

Childhood experiences

Home with natural surroundings

Home surrounded by urban elements

---
---
5
---
1

Passive interaction with plants

Active gardening

Demographics

Age

Education

Ethnicity

Gender

Income

${ }^{2}$ Variables that met the 0.05 significance level for entry into and removal from the model, based on a multivariate, stepwise logistic regression. Variables with (---) did not meet these criteria.

sis, the order in which a variable enters the model indicates its importance relative to the other variables in explaining responses to that item. Participation in active gardening during childhood was the most important variable in explaining respondents' perceptions of ethnicity, gender, and age, respectively. While those teaching gardening classes, obviously, cannot change these demographics, the results could be used to predict who might respond most to such activities or to target those who are less likely to appreciate the calming value of trees. The final variable to enter the model was childhood participation in environmental education or action. This indicates that children's gardening classes that include environmental education or activities to improve the local environment, such as planting trees to reduce erosion, should be beneficial in contributing to adult values toward plants.

Participation in active gardening during childhood also was the most important variable in explaining respondents' feelings that trees have personal meaning (Table 3 ). Gender was the second most important variable, followed by environmental education and age. The childhood variables of passive interaction with plants and being raised in a home with natural surroundings, such as flower beds or trees, were the last two variables to enter the model. These results indicated that any involvement with nature during childhood, whether active or passive, had positive value, but actively caring for plants had a stronger influence on adult attitudes than did passive involvement. The strong influence of active interaction with plants has long been suspected and assumed by people in this field, and these results verify it.

The most important variable to explain the likelihood of an adult participating in a gardening class or program was participation in active gardening as a child, the same variable that entered first in the models for the other two survey items (Table 3 ). This indicates the great importance and role of childhood active gardening, such as planting trees and picking vegetables, in promoting adult appreciation for gardening and the environment. The second most important variable was age, which also was a factor in the other models. Passive interaction with plants was the third most important in explaining the likelihood of taking a gardening class, showing that simply being around plants could influence adult actions. Education and a childhood home with natural surroundings were the least important influences for this item.

Current income and being raised 
in a home surrounded by urban elements were never important in explaining adult values or actions (Table 3 ). These factors, when analyzed alone, were shown to influence adult values, but not adult actions (Tables 1 and 2 ). The fact that they were not significant in the multivariate analysis indicates that their influence was easily overcome by other factors, such as participating in activities involving plants. This is an encouraging finding, indicating that children being raised in urban surroundings devoid of nature can benefit greatly from positive interventions with plants and gardening.

\section{Conclusion}

Childhood experiences with nature influence adult sensitivities to trees and that influence is very strong. Both active and passive childhood experiences with nature, such as picking vegetables and living next to a garden, had positive influences on adults' perceptions of the social and intrinsic values of trees and on their likelihood of taking a gardening class. Understanding this influence is particularly important, given that, in the future, more children will be raised in urban areas where chances to interact with nature may be limited. These results show that gardening and tree planting programs for children in surroundings devoid of nature can be effective in fostering the positive values that come from living with plants.

Participation in active gardening during childhood was consistently the most important influence in explaining adult attitudes and actions. Adults who spent more time during childhood in gardening activities were more likely to agree strongly that trees help people feel calmer and have personal value and to have taken a gardening class during the past year. Childhood participation in environmental education and passive interaction with plants, such as visiting parks, were also factors, but were less important in explaining these responses.

By understanding the relationships between childhood nature experiences and adult attitudes, we can better understand the value of tree planting and gardening programs for children on the perspectives of those same children as adults. These results indicate that horticultural programs for children can have great worth in helping children raised in urban surroundings with few or no plants. This information could be used to tailor children's environmental and gardening activities more effectively to engender appreciation for nearby nature in our adult citizens.

This research only begins to address these important relationships. It was based on memories of childhood nature contact and was designed to point the way to promising further studies, such as longitudinal ones. Many additional analyses of these data are possible (Lohr, 2004; Lohr and Pearson-Mims, 2002, 2004; Lohr et al., 2004a), and the raw data are available to other researchers for this purpose. More information on this project, its results, and the raw data are available at our web site (Lohr et al., 2004b).

\section{Literature cited}

Athman, J.A. and M.C. Monroe. 2001. Elements of effective environmental education programs. Eric Document Reproduction Serv. No. ED 463936.

Bullock, J.R. 1994. Helping children value and appreciate nature. Day Care Early Educ. 21(4):4-8.

Cooper Marcus, C. 1992. Environmental memories, p. 87-112. In: I. Altman and S.M. Low (eds.). Place attachment. Plenum Press, New York.

DeMarco, L.W., D. Relf, and A. McDaniel. 1999. Integrating gardening into the elementary school curriculum. HortTechnology 9:276-281.

Eberbach, C. 1990. School children: From recipients to participants. Public Garden 5:14.

Jaus, H.H. 1984. The development and retention of environmental attitudes in elementary school children. J. Environ. Educ. 15:33-36.

Kellert, S.R. 1996. American society, p. 37-63. In: The value of life: Biological diversity and human society. Island Press, Washington, D.C.

Lewis, C.A. 1996. Green nature/human nature: The meaning of plants in our lives. Univ. of Illinois Press, Urbana.

Lohr, V.I. 2004. Effect of childhood experiences with nature, including planting trees, on adult understanding of trees in cities. Acta Hort. 643:183-187.

Lohr, V.I. and C.H. Pearson-Mims. 2004. The relative influence of childhood activities and demographics on adult appreciation for the role of trees in human well-being. Acta Hort. 639: 253-259.

Lohr, V.I. and C.H. Pearson-Mims. 2002. Childhood contact with nature influences adult attitudes and actions toward trees and gardening. p. 267-277. In: C.A. Shoemaker (ed.). Interaction by design. Iowa State Press, Ames.

Lohr, V.I., C.H. Pearson-Mims, J. Tarnai, and D.A. Dillman. 2004a. How urban residents rate and rank the benefits and problems associated with trees in cities. J. Arboricult. 30:28-35.

Lohr, V.I., C.H. Pearson-Mims, J. Tarnai, and D.A. Dillman. 2004b. A multicultural survey of the influence of childhood environmental experiences on adult sensitivities to urban forests. 1 Oct. 2004. <http:// www.wsu.edu/ lohr/hih.nucfac/>.

Palmer, J. 1993. Development of concern for the environment and formative experiences of educators. J. Environ. Educ. 24:26-30.

Relf, P.D. and V.I. Lohr. 2003. Human issues in horticulture. HortScience 38:984-993.

SAS Institute. 1999. The logistic procedure, p. 1903-2042. In: SAS/STAT user's guide, version 8. SAS Institute, Cary, N.C.

Schwarz, N. and A. Tesser. 2001. Blackwell handbook of social psychology: Intraindividual processes. Blackwell, Oxford, U.K.

Skelly, S.M. and Zajicek, J.M. 1998. The effect of an interdisciplinary garden program on the environmental attitudes of elementary school students. Hort Technology 8:579-583.

Tanner, T. 1980. Significant life experiences: A new research area in environmental education. J. Environ. Educ. 11:20-24.

U.S. Census Bureau. 2000. Metropolitan area population estimates for July 1, 1999 and population change for April 1, 1990 to July 1, 1999. 12 Dec. 2001. <http://www. census.gov/population/estimates/metrocity/ma99-01.txt>.

United Nations. 2001. World urbanization prospects: The 1999 revision. Dept. of Economic and Social Affairs, Population Div. United Nations, New York.

Waliczek, T.M. and J.M. Zajicek. 1999. School gardening: Improving environmental attitudes of children through hands-on learning. J. Environ. Hort. 17:180-184.

Waliczek, T.M., P. Logan, and J.M. Zajicek. 2003. Exploring the impact of outdoor environmental activities on children using a qualitative text data analysis system. HortTechnology 13:684-688. 